\title{
Application of the Tecnomatix Plant Simulation Program to Modelling the Handling of Ocean Containers using the AGV System
}

\author{
Gabriel Fedorko \\ Technical University of Kosice \\ Faculty BERG \\ Institute of Logistics \\ Slovak Republic \\ e-mail: gabriel.fedorko@tuke.sk \\ Jiri Hanzl \\ Institute of Technology and Business \\ Department of Transport and Logistics \\ Faculty of Technology \\ České Budějovice, Czech Republic \\ e-mail: hanzl@mail.vstecb.cz
}

\author{
Martin Vasil \\ Technical University of Kosice \\ Faculty BERG \\ Institute of Logistics \\ Slovak Republic \\ e-mail: mato.vasil183@gmail.com
}

DOI 10.17818/NM/2018/4SI.12

UDK 621.798:656.61

Preliminary communication

Paper accepted: 28. 8. 2018.

\begin{abstract}
Summary
AGV systems, gradually making their way into individual logistics processes, represent an important tool for handling different types of cargo. Since their initial start in the domain of small handling units, their use has been incrementally finding its application in the area of large handling units, too, such as different types of containers. That is why an ever increasing number of them can be encountered at the range of land and sea reloading sites. Thus, there are many opportunities for them to be deployed in different types of logistics processes at maritime reloading sites. For the AGV system and the logistics processes to function correctly at each maritime reloading site, they need to be thoroughly fine-tuned. One of the methods that can be used effectively to that end is the method of computer simulation. The paper will describe how to create a simple simulation model using Tecnomatix Plant Simulation.
\end{abstract}

\section{INTRODUCTION}

With the increase in the volume of sea container transport, there are growing requirements for the efficient handling activities comprising individual logistics processes. At the same time, the main emphasis is placed on performance and time indicators. To meet these requirements, the various autonomous technologies are increasingly being applied, among which the most used are those based on the principle of automated guided vehicles (AGV).

Currently, AGV is one of the high performance tools in a wide range of logistics activities and processes associated with maritime container shipping [1]. However, their proper operation requires a whole range of necessary conditions be met, the first being the management of their transport routes [2]. In the framework of maritime terminals, the system of static transport routes was initially preferred for the operation of AGVs but was gradually replaced by dynamic route transport systems [3]. Dynamic guidance of AGV transport routes also brings to the fore the safety of operation and collision prevention [4]. Great impact on this issue has the way the AGV system management is done in individual operations. One of the possible ways is to use the dispatching management as described by Bian [5]. The application of dispatching control of AGV systems at sea container terminals has several problem areas to be addressed and studied [6].

A very important issue is also the method of assigning individual vehicles to carry out transport activities [7]. One of the possible solutions to this problem is the use of a hybrid method described by Zaghdoud et al. [8]. This is a very interesting issue, which is described in more detail by Corman et al. [9]. However, there are also other methods that are used to address the problems posed by the operation of AGV systems at sea container terminals. In particular, it is the genetic algorithm method [10].

Another method that can be used to solve the problems of container terminals using AGV systems is the computer simulation method [11]. This is a broad-spectrum method that can provide a wealth of information and knowledge about container reloading site behavior, AGV operations, and logistics processes [12]. Adequate simulation software should also be used to properly apply this method to model the required processes. Among the available simulation tools, Tecnomatix Plant Simulation offers vast possibilities for the AGV systems. 


\section{AGV SYSTEM APPLICATION TO HANDLING SEA CONTAINERS}

Sea containers are used in maritime and intermodal transportation for the transport of various types of cargo and freight [13]. The majority of goods is transported in this way around the world. However, handling sea containers is often not easy [14]. The most common way of their reloading from a ship to the terminal is by gantry cranes. Further, the containers are conveyed by AGVs to container docking blocks, where they are then handled by gantry cranes on the rails (Figure 1). In addition, the clamp transporters reload the containers further to semi-trailers.

Nowadays, AGV systems play an increasingly important role in the handling of sea containers [15]. Compared to conventional AGV systems that are used in various types of logistics processes, those driven at the maritime reloading sites are primarily powered by diesel engines [16]. In addition, their operation requires other factors to be taken into account, that are not accounted for in conventional AGV systems. In particular, it is the fact that AGV systems for handling sea containers move in an outdoor environment where they are exposed to weather conditions. For this reason, their individual structural components are impacted much more, higher demands are made of the motion components and the braking system.

When operating these devices, it is necessary to have different types of information so that their operation in logistics systems is as efficient as possible. We can divide the information we want into three categories:

- Performance - time indicators,

- Performance - length indicators,

- Capacity indicators.

All of these sets of indicators provide a comprehensive picture of the use of individual vehicles and the efficiency of their operation. These indicators can be used ex ante when planning the vehicle activities and designing complex logistics systems. However, they are much more often used in ex-post performance evaluation and implementation of a wide range of different types of analyses. In addition to classical analytical approaches based on observations, the computer simulation method can be used very efficiently, too.

\section{COMPUTER SIMULATION OF THE AGV SYSTEM IN LOGISTIC PROCESSES}

In simulating AGV network, handling the systems of sea containers in a variety of logistics processes, it is often necessary to define a number of restrictive conditions, or to work with information and indicators that the classical user version of the software tool does not use. One way to solve the problem is to modify the classic blocks that are available to regular users. This is a process that is very comfortable to use on the one hand. On the other hand, it puts higher demands on computer and programming skills. However, it should be emphasized that not all developers of simulation tools support such a solution. This is primarily because they protect their know - how on the one hand and, on the other hand, they also try to avoid problems that could be caused by such an interference due to ignorance of the algorithm or, inadequate programming skills to operate the simulation program.

However, there are solutions that can effectively eliminate these shortcomings and bring significant benefits to their users in creating simulation models. These include backing up simulation block libraries or using special blocks and dialog windows for writing commands in the respective programming language. One of the most effective solutions to this problem is Tecnomatix Plant Simulation.

\section{CHARACTERISTICS OF TECNOMATIX PLANT SIMULATION PROGRAM}

Tecnomatix Plant Simulation is a simulation program that is part of the Tecnomatix software package. Tecnomatix is a portfolio of programming tools with options covering the complex area of digital simulation solutions. In solving engineering problems, it can be applied at all stages from design and planning, through simulation and verification, to implementation and management itself. Plant Simulation is a software tool designed to simulate discrete events, helping to create complex digital models of different system types,

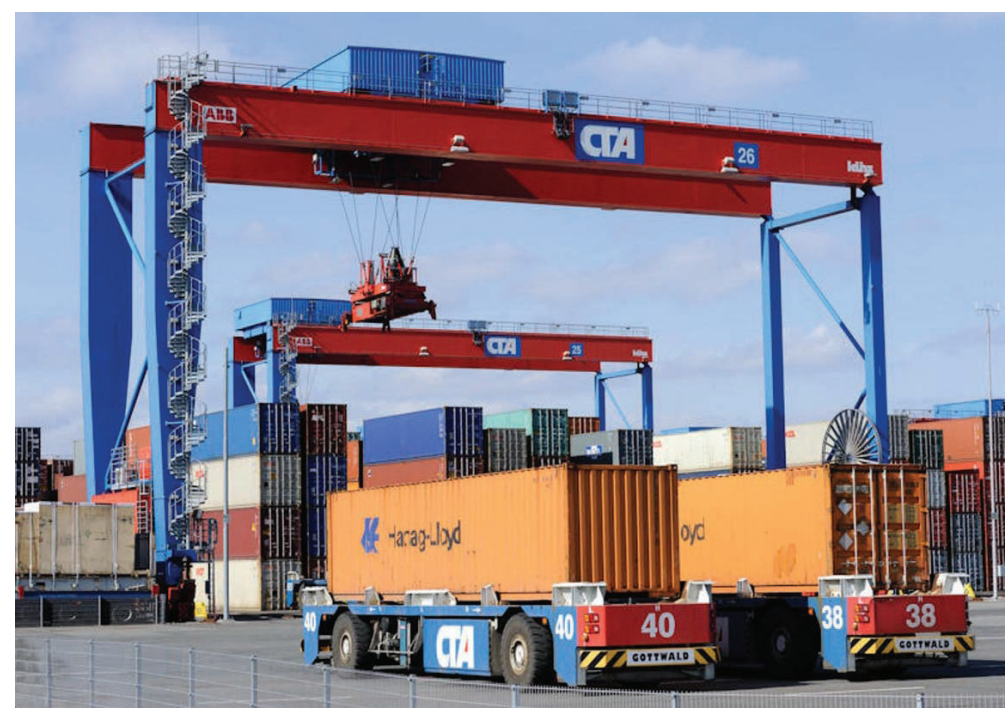

Source: [17]

Figure 1 Example of the AGV system deployment in sea container handling 


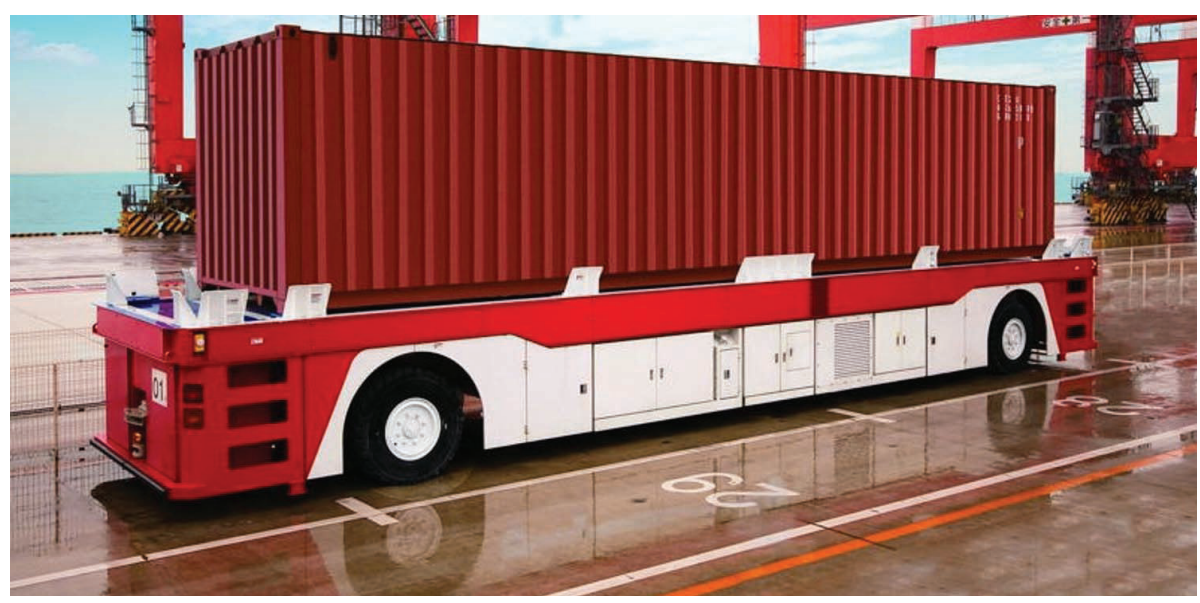

Source: [18]

Figure 2 AGV type used in simulation model

e.g. logistical, and allows for examination of their individual characteristics, for their optimization and evaluation.

These digital models make it possible to make extensive experiments and "what if" scenarios in the time available without disturbing the existing real systems. They also help to bring about planned and expected results long before installing the real production systems. They offer the possibility to optimize individual flows, use resources and logistics in all levels of planning.

To create individual simulation models, the program offers a wide range of blocks that cover the basic activities and operations. In order to achieve the most holistic approach to the real-time simulation model, the SimTalk programming language can be used and individual blocks can be programmed according to the user's requirements.

\section{AGV SYSTEM SIMULATION MODEL FOR HANDLING SEA CONTAINERS}

The simulation model describes the process of handling sea containers in a company which receives containers from the seagoing terminal semitrailers. Each container is subjected to an entrance check upon arrival in the company, it is then opened and unloaded according to the instructions, or it is prepared for further shipment. Container handling is carried out using a fleet of autonomous vehicles, the number of which canvary flexibly (Figure 2).

The individual container shipments are handled by staff performing a well-defined portfolio of operations. The personnel aspect of the simulation model is designed to reflect the real employment and shift work. All these processes are executed with the WorkerPool block. The Brooker block

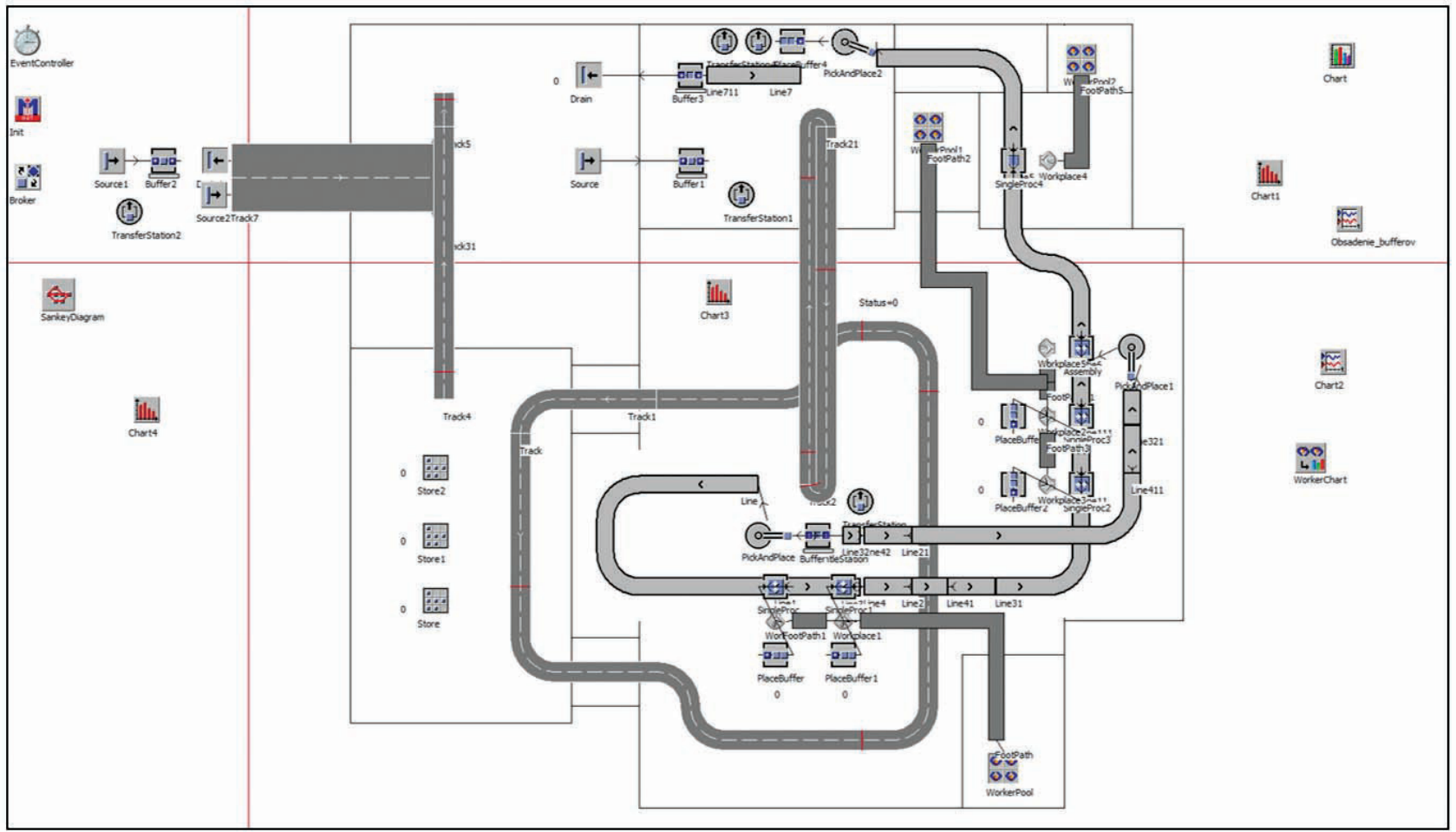

Source: authors

Figure 3 Basic concept of the AGV system simulation model for handling sea containers 

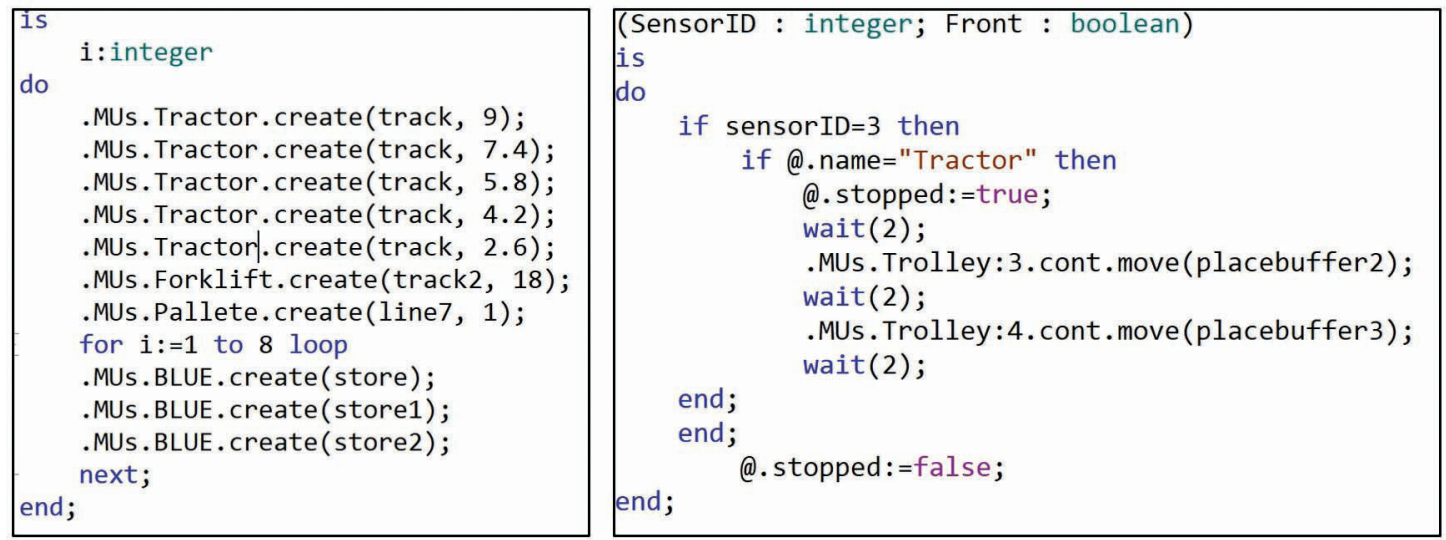

Source: authors

Figure 4 Demonstration of SimTalk Additional Programming Method Applied to the Simulation Model

is responsible for the allocation of individual activities. In addition, there are several TransferPoints in the simulation model, which ensure container or cargo reloading. The overall view of the simulation model is shown in Figure 3.

In addition to AGVs designed to handle containers, the use simulation model also includes forklift trucks. These resources are always generated in the simulation model at the beginning of the simulation experiment using the SimTalk addon programming method that is written in the Method block. At the same time, individual constraints and manipulation processes were programmed in SimTalk (Figure 4).

The Method block above can be briefly described as a notebook in which the add-on program can be written. Subsequently, the Method block is connected to the desired location in the simulation model, where the program needs to be deployed. When running the simulation, the program identifies that the Method block has been used and thanks to the relevant link, it reads and executes the prescribed program.

Traffic routes for the AGV and forklift movement are defined statically. Routes are planned as one way courses. Only AGVs, or forklifts, can move alongside the routes, but they cannot overtake each other. Individual AGVs in the simulation model are modeled by means of Mus Transporter blocks.

\section{AGV MODELLING FOR HANDLING SEA CONTAINTERS}

In the simulation model, the AGVs are represented by the MU's Tractor. This is an element that is an integral part of the Tecnomatix Plant Simulation Class Library. Its mission in the model is to simulate various vehicles, transport and handling equipment. Parameter setting for the AGV system was implemented through dialog windows shown in Figure 5.

\section{APPLICATION OF THE SIMULATION MODEL AND THE INFORMATION OFFERED}

The simulation model was designed as to be used to evaluate the process of planning individual logistics processes in the company. The first analysis was the monitoring of material flows within the executed logistics processes (Figure 6). Sankey's diagram was chosen as the main visualization tool.

The results have shown low efficiency of using a storage location labeled as Store. This was due to its specialization

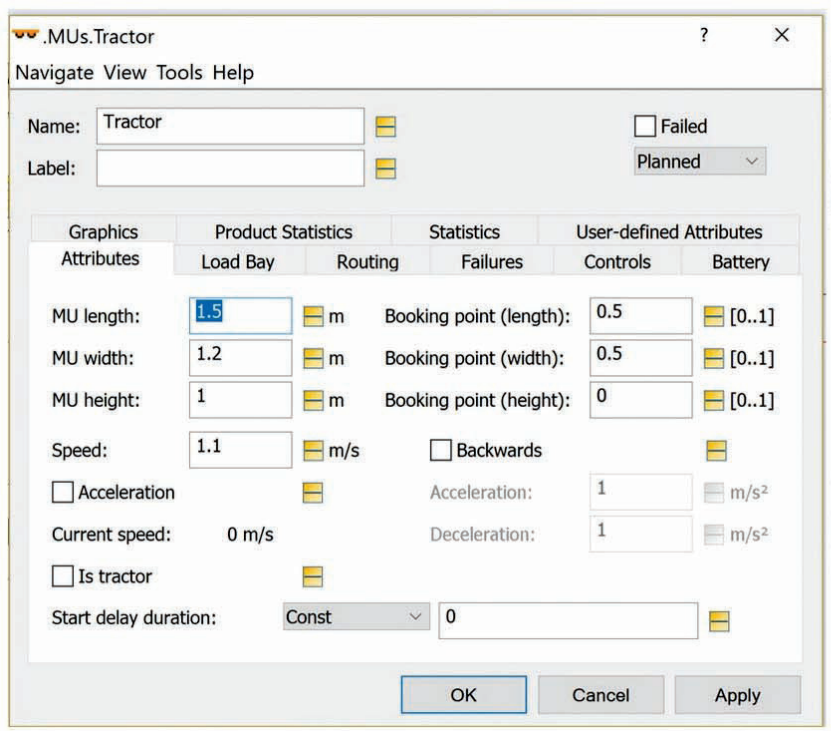

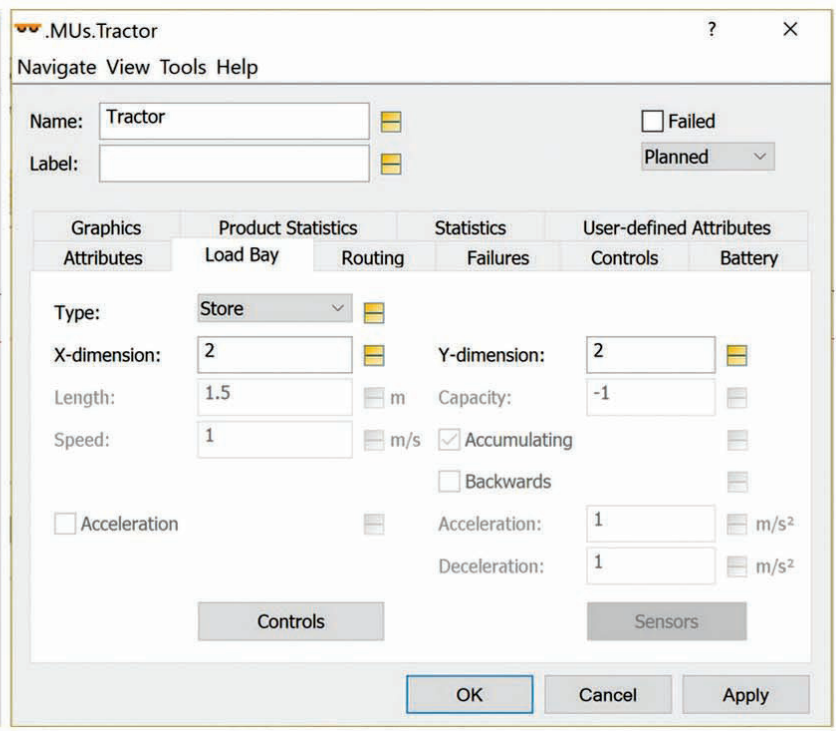

Source: authors

Figure 5 MU's Tractor dialog window 


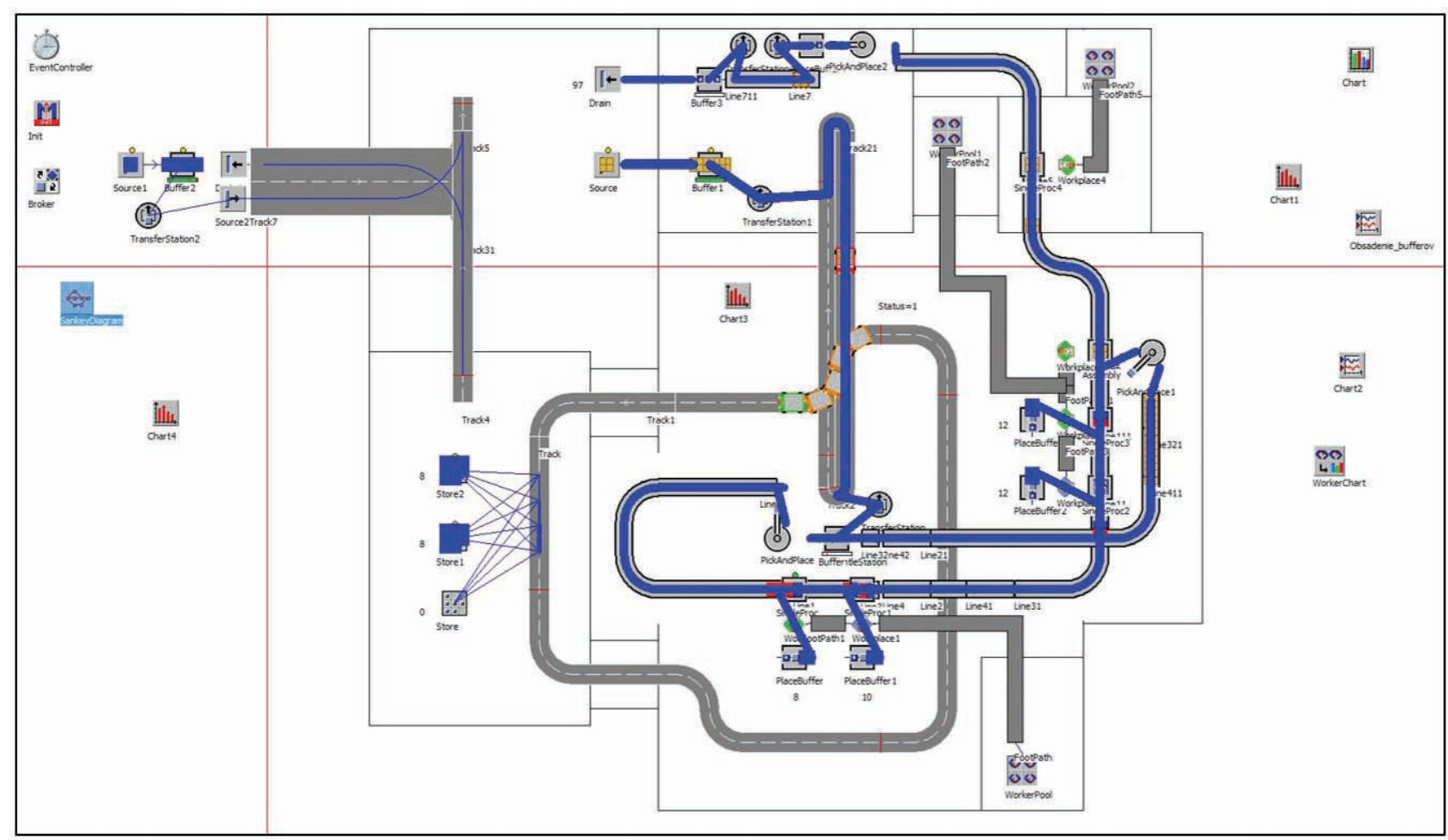

Source: authors

Figure 6 Sankey's diagram

because it was a storage space for a specific type of goods, necessary for a trouble-free operation of the company. Blue lines of various boldness show the routes used by the AGVs to convey sea containers and the movement of the material that had already been unloaded from these containers. Thus, we can clearly see the sections of transport routes with the heaviest traffic.

In addition, the results of the simulation experiment provided the material for the analysis of the use of three handling devices used in the implementation of individual logistics operations with goods obtained from sea containers (Figure 7).

The results of the analysis point to the uneven usage of individual devices. In particular, the device labeled PickAndPlace 1 was most used. Its utilization was almost 75\%, while the remaining two devices were used only minimally,
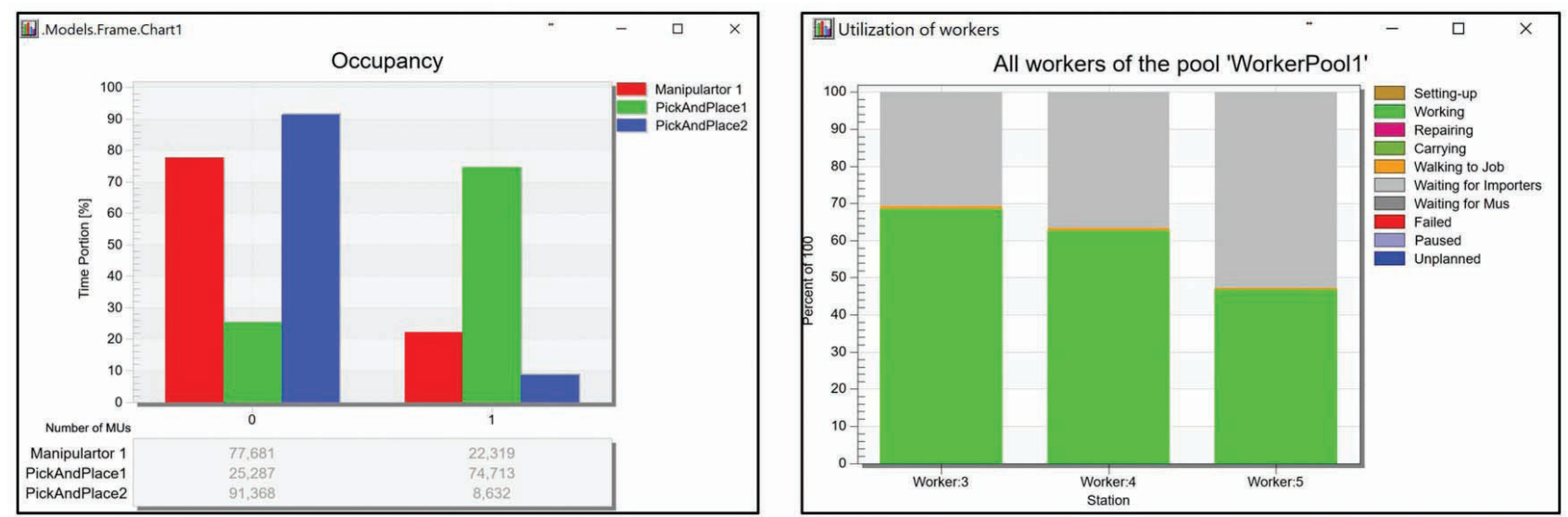

i.e. $22 \%$ and as little as $8 \%$ of the time, which opened up a discussion regarding their use, i.e. or whether the operation should be carried out by one of them.

In addition to the utilization of the individual handling equipment during the logistic operations connected with the sea containers, the workload of the workers at individual workplaces was examined (Figure 7). From the results obtained, it can be stated that the workload of the employees is sufficient for the fulfillment of the work duties and ensuring the reliable operation of the individual logistics processes. At the same time, it should be added that individuals also have sufficient time resources to solve operational and unplanned tasks.

Further attention in the simulation model was devoted to the evaluation of performance and activity of individual warehouses and buffers (Figure 8). The simulation model

Source: authors

Figure 7 Demonstration of information visualization obtained through a simulation experiment 

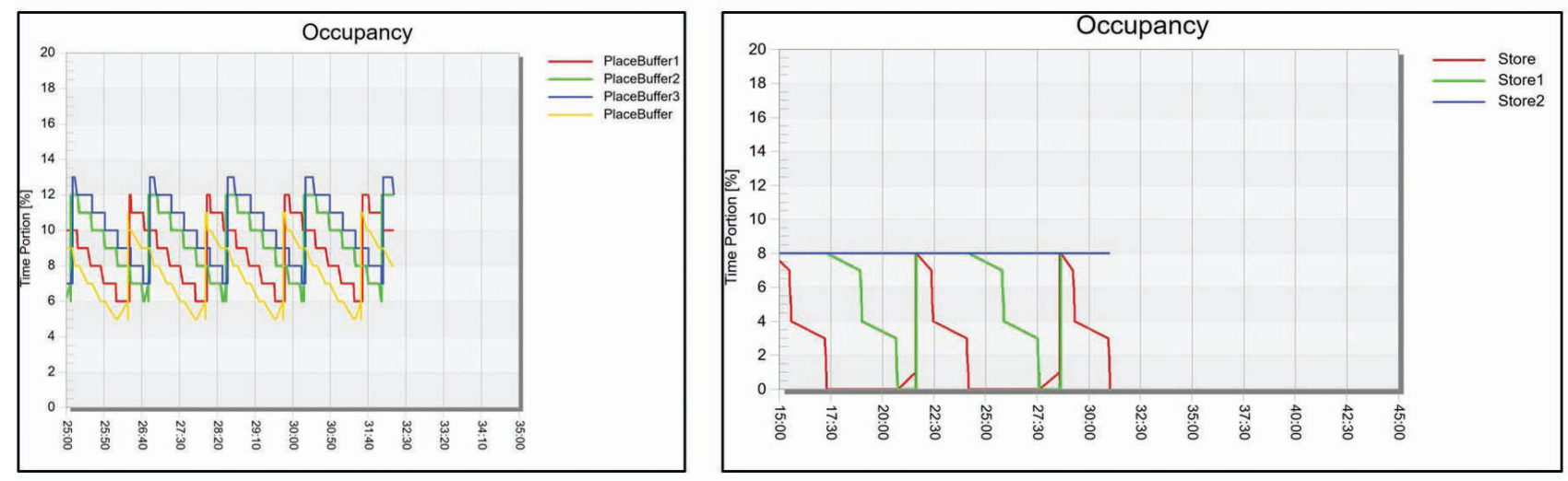

Source: [3]

Figure 8 Utilization of individual warehouses and buffers

allowed for tracking every movement of the material at these locations. Inventory values varied due to new deliveries made by autonomous vehicles $[19,20]$.

In addition to the above parameters, additional indicators could be tracked using the simulation model. These were, specifically, the utilization of individual AGVs, their mileage and a number of other evaluation indicators. Overall, the model was designed to be maximally flexible and sensitive to any eventual new needs and requirements related to the AGVs operation and handling of individual sea containers.

\section{CONCLUSION}

The use of AGVs to ensure logistics processes has an increasing trend. AGVs perform their mission very efficiently and help maintain reliability. They are deployed not only in production halls, but also in outdoor environments, include shipping and handling of sea containers at sea terminals included. Their deployment in the handling of sea containers is increasingly more common and the autonomous vehicles fulfill a wide range of transport tasks.

However, their proper functioning is subject to different types of analyzes and assessments. Those can draw on ongoing operational logs, but also on the results of computer simulation.

Nevertheless, computer simulation of AGVs handling sea containers is challenging both for the software used and the structure of the model itself. For this reason, it is necessary to apply various methods and approaches, including the addon programming method.

The implementation of add-on programming method in the simulation software significantly increases the possibilities for the creation of simulation models of logistic and technological processes, the handling of sea containers included. Thanks to it, even the most complex logistics and technological processes and their parts executed at reloading land terminals can be simulated.

Although add-on programming requires at least basic coding knowledge, it does not in any case discriminate against those who lack it altogether. A large number of intuitive tools in add-on programming significantly helps the users in their work with it and at the same time indirectly teaches them the subject matter and improves their abilities and skills. At the same time, the add-on programming allows for individual simulation models to be fully compatible with the requirements of the industry 4.0 philosophy and the associated Digital Enterprise.

\section{Acknowledgement}

This work is a part of the following projects VEGA 1/0063/16, VEGA 1/0403/18, KEGA 018TUKE-4/2016, APVV 17-0235.

\section{REFERENCES}

[1] Rui, Y., Wei, Z. Research and Application for Key Technologies of Containe Automated Guided Vehicle (AGV) at Port. In: Proceedings of the 2016 6th International Conference on Applied Science, Engineering and Technology (ICASET), 2016, Qingdao, China, pp. 87-91.

[2] Duinkerken, M.B., Lodewijks, G. Routing of AGVs on Automated Containe Terminals. In: Proceedings of the 2015 IEEE 19th international conference on computer supported cooperative work in design (CSCWD), Engineering and Technology (ICASET), 2015, Calabria, Italy, pp. 401-406.

[3] Jeon, S.M., Duinkerken, M.B., Lodewijks, G. Dynamic routing strategies for automated container terminals. In: European simulation and modelling conference 2009, EUROSIS, 2009, Ghent, Belgium, pp. 109-113.

[4] Bae, H.Y., Choe, R., Park, T. , Ryu, K.R. Travel time estimation and deadlock-free routing of an AGV system. In: Dynamics in logistics, 2008, Bremen, Germany, pp. 77-84.

[5] Bian, Z., Yang, Y., Mi, W., Mi, C. Dispatching Electric AGVs in Automated Container Terminals with Long Travelling Distance. Journal of coastal research, 2015, Vol. 2015, No. 73, pp. 75-81. ISSN 0749-0208.

[6] Klerides, E., Hadjiconstantinou, E. Modelling and solution approaches to the multi-load AGV dispatching problem in container terminals. Maritime economics \& logistics, 2011, Vol. 13, No. 4, pp. 371-386. ISSN 1479-2931.

[7] Gujjula, R., Guenther, H.O. The impact of storage block assignment for import containers on AGV dispatching in highly automated seaport container terminals. In: IEEM: 2008 International conference on industrial engineering and engineering management, 2008, Singapore, pp. 1739-1743.

[8] Zaghdoud, R., Mesghouni, K., Dutilleul, S. C., Zidi, K., Ghedira, K. A Hybrid Method for Assigning Containers to AGVs in the Dynamic Environment of Container Terminals. Studies in informatics and control, 2015, Vol. 24, No. 1, pp. 43-50. ISSN 1220-1766.

[9] Corman, F., Xin, J., Toli, A., Negenborn, R., D'Ariano, A., Sama, M., Lodewijks, G. Optimizing hybrid operations at large-scale automated container terminals. In: 2015 International conference on models and technologies for intelligent transportation systems (MT-ITS), 2015, Budapest, Hungary, pp. 514-521. https://doi.org/10.1109/MTITS.2015.7223302

[10] Dkhil, H., Yassine, A., Chabchoub, H. Optimization of Container Handling Systems in Automated Maritime Terminals A hybrid genetic and a tabu search algorithms. In: 2013 International conference on advanced logistics and transport (ICALT), 2013, Sousse, Tunisia, pp. 539-544. https://doi.org/10.1109/ ICAdLT.2013.6568516

[11] Henesey, L., Davidsson, P., Persson, J.A. Evaluation of Automated Guided Vehicle Systems for Container Terminals Using Multi Agent Based Simulation. In: MABS 2008: Multi-agent-based simulation IX, 2009, Budapest, Hungary, pp. 85-96.

[12] Lizbetin, J., Stopka, O. Practical application of the methodology for determining the performance of a combined transport terminal. In: 2016 3rd 
International Conference on Traffic and Transport Engineering (ICTTE), 2016, Beograd, Serbia, pp. 382-387.

[13] Torok, A., Torok, A., Heinitz, F. Usage of production functions in the comparative analysis of transport related fuel consumption. Transport and Telecommunication Journal, 2014, Vol. 15, No. 4, pp. 292-298. ISSN 1407-6179.

[14] Torok, A. Comparative analysis between the theories of road transport safety and emission. Transport, 2017, Vol. 32, No. 2, pp. 192-197. ISSN 1648-4142.

[15] Ližbetin, J., Caha, Z. The Optimization of the Intermodal Terminals. Nase more, 2015, Vol. 62, No. 3, pp. 97-100. ISSN 0469-6255.

[16] Stopka, O., Kampf, R. Determining the most suitable layout of space for the loading units' handling in the maritime port. Transport, 2016, Vol. 31, No. 0 , pp. 1-11. ISSN 1648-4142.
[17] Belin, Ch. Bildarchiv Hamburg. [online], 2018, Available via: http://www. bildarchiv-hamburg.de/folders/HHLA\%20Container\%20Terminal\%20 Hamburg\%20Altenwerder\%20(\%20CTA\%20)/0450-1164_hhla-containerterminal-arbeit-im-hamburger-hafen.jpg.

[18] Götting KG. Goetting. [online], 2018, Available via: http://www.goetting-agv. com/dateien/galerienbilder/Anwendungsbeispiele\%20Transponder\%20 004.jpg.

[19] Brumercik, F. Discrete event simulation of logistic and transport systems. Logi - Scientific Journal on Transport and Logistics, 2011, Vol. 2, No. 1, pp. 5-10. ISSN 1804-3216.

[20] Gerigk, M. Challenges associated with the design of a small unmanned autonomous maritime vehicle. Scientific Journals of the Maritime University of Szczecin, 2016, Vol. 46, No. 118, pp. 22-28. DOI: 10.17402/113. 